\title{
Navigating the Virtual Forest: How Networked Digital Technologies Can Foster Transgeographic Learning
}

\author{
Nicole A. Buzzetto-More \\ University of Maryland Eastern Shore, Princess Anne, MD, USA
}

Nabuzzetto-more@umes.edu

\begin{abstract}
During the past decade the globally networked digital technologies that operate within the realm of the internet have encouraged academicians and educators the world over to communicate, collaborate, and share knowledge. They have stimulated the creation of transgeographic educational initiatives which broaden the opportunities of learners and are an effective means of eradicating ethnocentrism, xenophobia, and cultural divides.
\end{abstract}

The construction of transgeographic learning communities within the unmapped virtual forest of the internet requires an organized and systematic approach. Success is dependent on committed participants; a shared learning platform; a clear understanding of purpose; extensive student and instructor preparedness towards technology usage; exemplary curricula; a central focus for investigation; interaction with experts; extensive opportunities for intellectual discourse; and collaboration.

The purpose of this paper is to offer an independent examination of a successful technologydependent transgeographic learning project that serves as a model from which to base future projects. The Summer Ecosystems Experience for Undergraduates (SEE-U) is available to colleges and university students worldwide, operating at three geographically distinct locations concurrently. The program includes global networking, GPS and GIS usage, a shared investigative focus, real-time interactions, data collection, a globally networked geo-referenced digital database that was specifically created for this project, data manipulation, online lectures, bulletin board discussions, Web-based office hours, links to relevant resources, expert presenters, online demonstration videos, networked simulations, collaborative research, and a series of student presentations.

Keywords: Information Communication, e-Learning, Co-operative Learning, Global Education, Distance Education, Global Networking, Instructional Technology

\section{Introduction}

Material published as part of this publication, either on-line or in print, is copyrighted by the Informing Science Institute. Permission to make digital or paper copy of part or all of these works for personal or classroom use is granted without fee provided that the copies are not made or distributed for profit or commercial advantage AND that copies 1) bear this notice in full and 2) give the full citation on the first page. It is permissible to abstract these works so long as credit is given. To copy in all other cases or to republish or to post on a server or to redistribute to lists requires specific permission and payment of a fee. Contact Publisher@InformingScience.org to request redistribution permission.
The Summer Ecosystems Experience for Undergraduates, otherwise known as SEE-U, is a model of the how information technologies can be used to foster global education. It operates under the auspices of Columbia University's Center for Environmental Research and Conservation, CERC, an organization comprised of world-class scientific institutions. It was created through a collabo- 
ration with the Columbia Center for New Media in Teaching and Learning, an instructional technology- development center housed at Columbia University; the Center for International Earth Sciences Information Network, an organization that seeks to use information technology to enhance the worldwide effort to examine the impact of humans on the environment; and the Black Rock Forest Consortium, a unique and powerful amalgamation of distinguished academic institutions and science and cultural centers that successfully collaborate to enhance scientific research and education.

The SEE-U program was piloted in the summer of 2000. Since that time it has attracted students from across the globe. It is offered in three locations concurrently and is an in-depth field and technology-based introduction to ecology, and environmental studies.

Technologies are used in interesting and innovative ways serving as an example for other courses. Students participating in the SEE-U program take advantage of Geographic Position System (GPS) technology to spatially reference data; Geographic Information System (GIS) technology to allow detailed mapping and topographical representation of data; modeling software for the visualization of and experimentation with data; detailed computer networking; online research; digital lectures and demonstration videos; synchronous and asynchronous discussions with students across geographic borders; and an advanced database technology that is multi-query able. Operating across field sites, students use the power of networked digital technologies to compare and analyze data, develop hypothesis, and communicate and collaborate with learners that are geographically distant.

\section{Literature Review}

The current impact of technological innovation extends farther and deeper than at any other time in our history. These advances have altered the very constructs of space and time and have changed visibility, making it global in scope. The result has engendered a growing number of international learning communities. These communities open up a world of educational possibilities replete with symbolic interactions that cross geographic borders. Through well-developed globally networked technologies, educators and learners worldwide interact in courses and projects that cross cultural divides, encourage collaboration, develop broader perspectives, and foster intellectual discourse (Buzzetto-More, 2005).

Research conducted by McIsaac (1993) found that the use of information technologies in the fostering of global education is a highly effective means for encouraging educational empowerment. He explained that, although numerous methodologies can be employed in the use of networked digital technologies to create global learning communities, there are issues that must be addressed. According to McIsaac, these issues include language; pedagogy; technological accessibility, usability and reliability; motivation; and project cost and practicality.

Research studies have shown that people learn through meaningful interactions with others (Johnson \& Thomas, 1994). A major goal of global education is the creation of learning communities that use technology to stimulate meaningful discourse between and among cultures (McIsaac, 1993). Bhatti, Tubaishat, and El-Quawasmeh (2005) found that technology mediated learning environments can help students overcome social and cultural limitations in higher education.

Technology and global-education partnerships can provide students with nontraditional learning experiences, and perhaps no subject matter is better suited for technology incorporation then science education (Buzzetto-More, 2005).

Skeptics often point out the hands-on nature of scientific study as a deterrent; however, Peter Fenrich (2005) of the British Columbia Institute of Technology found that when simulations, active 
experimentations, discovery-based learning, interactivity, questioning, feedback, collaboration, and animated models are used, one can successfully teach hands-on skills virtually.

Digital technologies are allowing for more creative and innovative science education that goes beyond the traditional drill and memorization of facts (Lemke in Scalpter, 1998). Kastens (1999) explains that the current goal is to take environmental learning away from the pre-packaged lab and decontextualized textbook-based lessons and transform ecology education by linking science education to scientific practice. Bridging the gaps between learners and scientists is done through the use of real data, hands-on experimentation, the examination scientific processes, modeling, and access to actual working scientists (Buzzetto-More, 2004).

Technology is considered by many to be a means of assisting in the delivery of authentic learning experiences in ecology studies. According to Cheryl Lemke (Scalpter, 1998), technology facilitates the study of science by increasing the scope of available resources, allowing for expedient and reliable access to data and research materials, enhancing collaboration, encouraging systems thinking, and by effectively delivering curriculum.

Kim Kastens of Lamont Doherty Earth Observatory discusses the need to make science education authentic and the role that technology plays in facilitating this effort (1999). Kastens (1999) illustrates that technology helps students imitate the method of inquiry practiced by actual working scientists which in turn makes learning more authentic.

The movement from traditional learning to technology enabled learning has been explained as a move towards the constructivist educational model (Lewis, MacEntee, DeLaCruz, Englander, Jeffrey, Takach, Wilson, \& Woodall, 2005) where learning involves collaboration, social discourse, problem solving, exploration, anchored instruction, critical thinking, intellectual discourse, knowledge construction, and scaffolding (Koohang and Harman, 2005).

Kaplan and Black (2001) found that visual mapping technologies help students build effective mental models. Black (1995) explained that through mental models students make observations; engage in visualization; construct interpretations of their observances; use references to contextualize the information; and gain permanence and transferability by being exposed to multiple representations of the knowledge.

Black, Hachey, and Tseui (2001) conducted studies that found that computer-based learning tools enhance student development of scientific reasoning skills by encouraging students to apply skills in meaningful scenarios.

This concept of using technology to immerse students in the scientific process has been echoed by Dede (2000) who noted that the careful design of virtual learning environments that immerse students in the scientific process help build deep understandings of complex scientific knowledge.

Sarapuu (n.d.) has explained the role that technology plays in enhancing the science learning process. He found that computerized learning in science education helps students with memory, comprehension, analysis, and the application of scientific knowledge.

Access to scientific resources and professionals is certainly not equitable. According to White and Frederiksen (2000), technology can serve as an equalizer that makes scientific knowledge more accessible to learners.

The benefits of technology-facilitated global education include: increased exposure to, and understanding of, different cultures so as to combat ethnocentrism; opportunities to prepare learners to enter what is increasingly a global workforce; the fostering of intercultural communications skills; the offering of unique insights through exposure to global perspectives; the development of the preparedness skills that facilitate student collaboration; and the building of necessary technological skills (Buzzetto-More, 2005). 
When information communication is used to create global education, it can include a multitude of technologies. Requisite, however, is that the technology is networked; well developed and educationally relevant following student-centered design principles; that it be tested prior to implementation; contain a discussion section and a shared workspace; is user-friendly; includes easily accessible technology support; and has a backup plan in the event of technology failure (BuzzettoMore, 2005).

In order for technology-facilitated global learning experiences to be successful, they should include a central question for investigation; a shared online learning platform; a clear understanding of purpose; extensive student and instructor preparedness for technology usage; interaction with professional experts; a discussion forum; and a collaborative project that is shared among participants (Buzzetto-More, 2005).

\section{Discussion}

\section{Curriculum}

The five-week SEE-U program is a total immersion course based on the pedagogical concept of anchored instruction. It is held at several locations simultaneously, including the Black Rock Forest in New York State, the Atlantic Forest in Brazil, and Punta Cana in the Dominican Republic, with plans to expand to Kenya. During this field ecology course learners explore biomes globally and locally.

The course is open to undergraduate students across the globe, regardless of college major. Interested students visit the SEE-U website, found at http://www.columbia.edu/itc/cerc/seeu. From the website students can request information or download an application. The website also includes the program’s curriculum, field site information, and slide shows. (See Figure 1.)

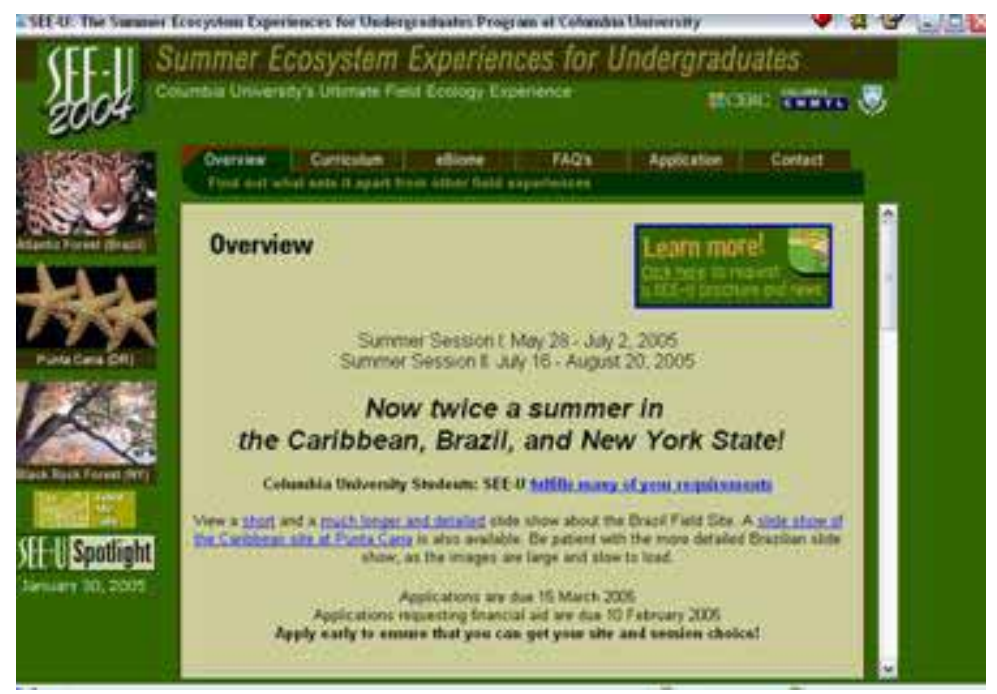

Figure 1: SEE-U Homepage, courtesy of SEE-U/ CERC

Scientists rarely work independently or in isolation from other scientists. As a result, participants in the SEE-U program conduct scientific research and make discoveries in cooperative learning groups. Collaboratively, the learners create presentations that result in their sharing of findings and entering into discourse with students located remotely. Because success for the students is 
largely dependent on collaboration, learners develop an understanding that science is a cooperative practice.

The students begin with background information and a shared question for investigation. Throughout the course they research the question by gathering data and testing out different hypotheses in the same manner as professional scientists. The goal of the hands-on experimental aspect of the SEE-U course is designed to help students to develop and build scientific research skills.

The SEE-U curriculum comprises four major sections, namely, biomes, biotic processes, a biotic processes, and contemporary issues. Biomes covers the understanding of the world's major biomes, the different biomes represented by the participating field sites, and provides an in-depth focus on the local biome where the students are immersed. The section on biotic processes includes natural selection and evolution; growth and competition, otherwise known as population dynamics; community ecology; and the basis of ecosystems. A biotic processes, covers the role of light and temperature, geology and soils, chemical and hydrological cycles, and geological disturbances. Contemporary issues, focuses the social, political, and ethical issues that are of concern to their respective biome as well as to the other field sites.

Within each section, topics are broken down into modules. In total there are 16 modules, each taking one or two days to cover. The learning modules include experiments, and throughout the five-week course the learners participate in roughly 20 experiments.

During the experiments, learners enter the field and collect data, later conducting simulations and modeling to analyze their findings. Students work with both archived and new data - seeking, analyzing, and learning from networked information - presenting the total of their work.

Most educational theorists agree that intellectual discussion facilitates learning. The learners in the SEE-U program have symbolic interactions with their counterparts located at the remote field sites. Throughout the program they enter into relevant discourse as they participate in online discussions, take part in collaborative research, share and compare findings, conduct networked simulations, and hear and participate in lectures and discussions given by scientists across the globe.

\section{Technology Use}

The SEE-U program uses technology in the acquisition, analysis, modeling, and comparison of data and also to foster communications, collaborations, discussions, debate, and the delivery of curricula. Participating students use Geographic Position System (GPS) technology to spatially reference data; Geographic Information System (GIS) technology for the mapping and topographical representation of data; modeling software for the visualization of and experimentation with data; web based research databases; digital lectures and demonstration videos; synchronous and asynchronous discussions; and an advanced database.

Although the SEE-U program is a field course, it is designed and delivered in many ways as a distance-learning program. Course information is completely delivered online, including lecture notes, slides, text, video, web links, database access, discussion-board availability, live chats, and subscriptions to relevant online scientific publications. The benefits of the online delivery of information are increased access to materials, accuracy in delivery, and the ability for students to visit and revisit course information according to need and interest (Buzzetto-More, 2004).

Global networking allows the learners to communicate and collaborate across all of the program's biological field sites as students share data and work on research projects together. As a result, this course helps illustrate the global nature of the scientific community and the importance of sharing and comparing discoveries with other scientists. 


\section{Ebiome}

At the core of the Summer Ecosystems Experience is the use of EBiome, which is a geo-spatially referenced database that is available through the global network to all program participants. During the program, participants embark to the field and collect data using GPS instrumentation. GPS technology involves the use of radio signals received from at least four satellites that exist in geosynchronous orbits circling the Earth. GPS makes it possible to pinpoint exact locations where data is collected. Student use the GPS system to determine the precise latitude and longitude where data are collected.

Upon returning to base station the students input their data into the specially designed EBiome database. Datasets in EBiome can be reference and compared spatially, topically, or by biome. For example, users may search data-sets by any number of characteristics such as data type, by spatial reference, and or by the date or time of the data collection. Users can set parameters for querying data such as soil $\mathrm{ph}>6.4<3.2$. Additionally, Ebiome includes copious amounts of metadata elements, which help to insure data accuracy and integrity and allow for additional forms of inquiry. According to CERC the benefits of Ebiome are the storage of data for longitudinal study and comparison, the referencing of data and compilation in a digital repository, the georeferencing of data, the amount of metadata included, and that students take part in the datacollection process. (See Figure 2.)

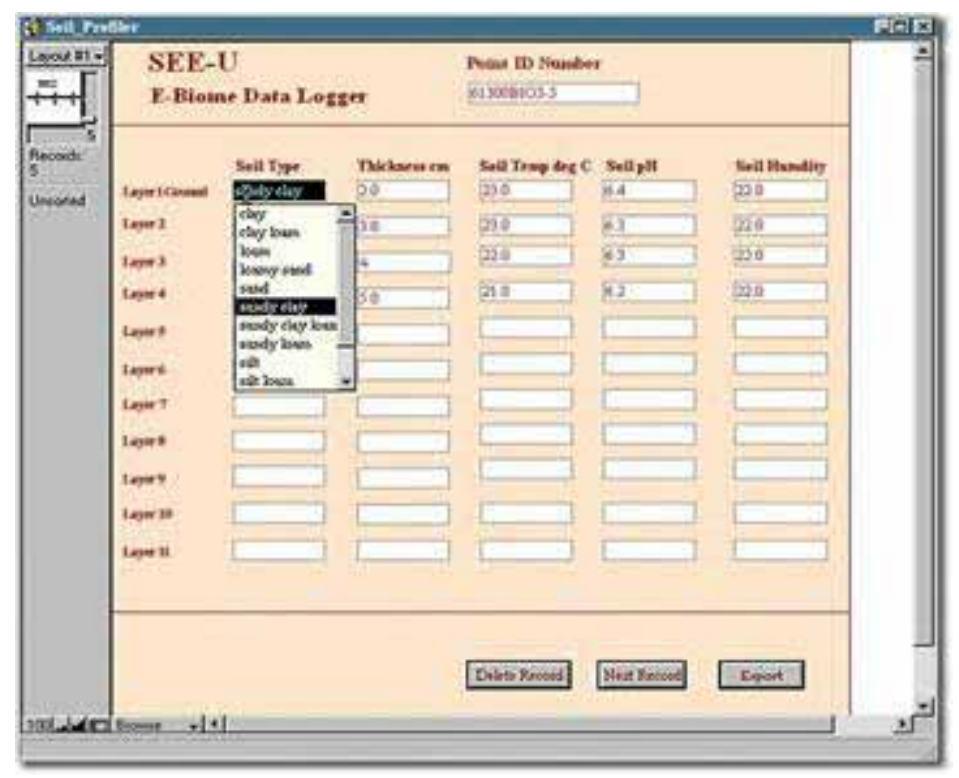

Figure 2: E-Biome Data Logger, courtesy of SEEU/ CERC

EBiome is a unique digital database that is designed to serve as a central repository to what is, increasingly becoming significant and copious amounts of longitudinal data.

EBiome was created specifically for the SEE-U program and is one of the most unique and integral parts of the course. EBiome was created by the Center for Environmental Research and Conservation (CERC), the Columbia Center for New Media in Teaching and Learning (CCNMTL), and the Center for International Earth Sciences Information Network (CIESEN).

All of the data collected as part of the student investigations is entered into EBiome and can be accessed by all who are participating in the program onsite or remotely, as well as by instructors and research scientists the world over. 
Students participating in the SEE-U program compare their data to archival data and to data collected by their counterparts at the remote field sites. The students discuss information across locations as they enter into relevant discourse through interactions with learners via the global network at the other biological field sites. At the same time, the students are given the opportunity to assist some of the world's leading scientists in their efforts.

Students enrolled in the SEE-U course are well versed in the use of Ebiome. Prior to working with the technology, students are trained in its proper use and many features. This training is built directly into the course curriculum.

\section{GIS}

Ebiome allows data to be represented spatially, using Geographic Information System (GIS) technology. GIS is a dynamic mapping system that allows individuals to collect, manage, and spatially reference volumes of data. GIS involves a series of aerial photos that have been digitized allowing for the construction of elevation models. Additional information is later entered on roads, trails, streams, landmarks, and other features that may not be included in aerial photos. Information displayed in GIS involves the overlaying of maps where individual map layers represent geological characteristics.

The GIS program used by SEE-U was specifically designed and formatted for use by SEE-U. For this project, the information is accessible using the ESRI Arc View Software and a Trimble GeoExplorer mapping system which serves as the field receiver that accepts the GPS information. (See Figure 3.)

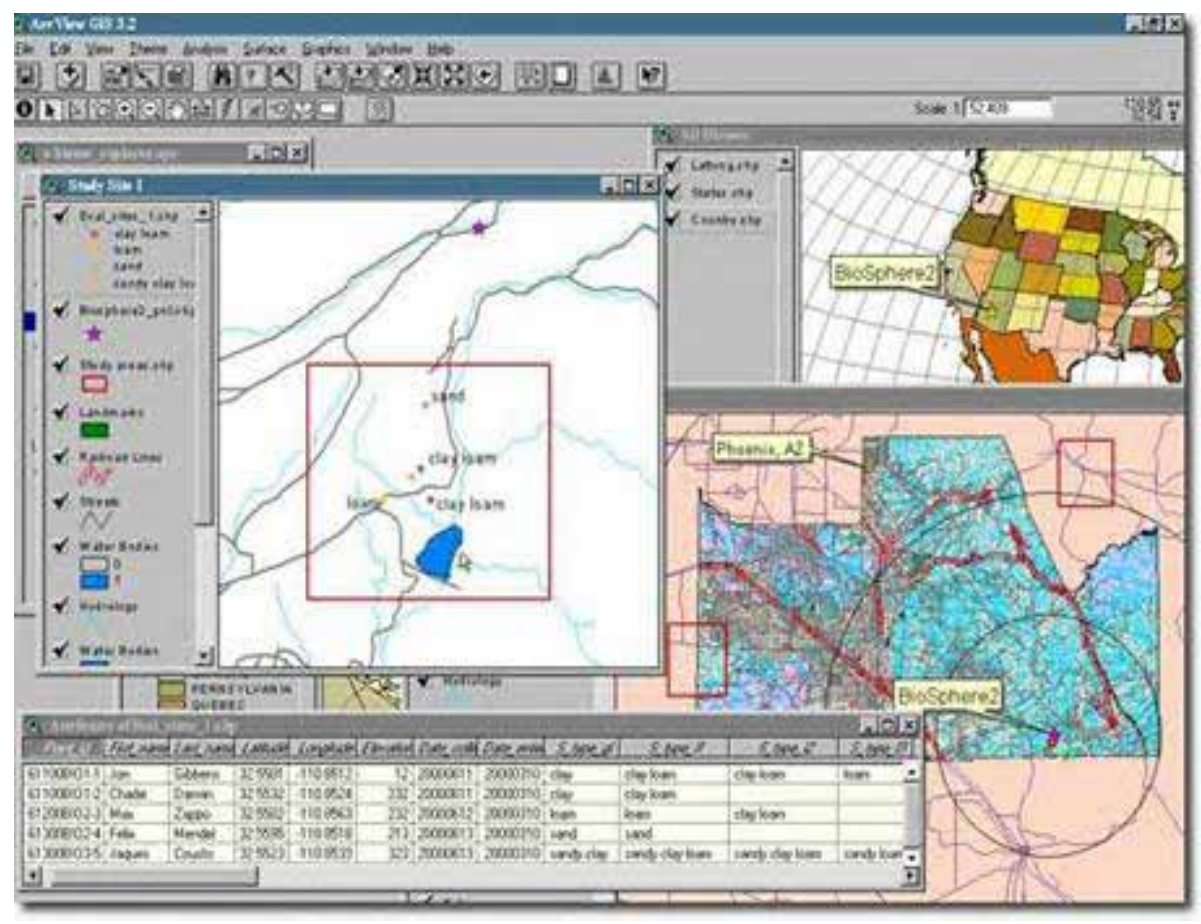

Figure 3: Arc View, courtesy of SEEU/ CERC

\section{Program Goals}

According to CERC, when students complete the SEE-U curriculum, they have developed a mastery of several key concepts, including, an understanding of the scientific method and its underly- 
ing theory; knowledge of the multilevel interaction of ecological elements and an appreciation of the importance of not disturbing these relationships; an understanding of the human impact on the environment; insight on the interaction of the world's biomes; illustration of ecological and biological diversity; comprehension of population dynamics; knowledge of the chemical cycle within an ecosystem; the ability to work with cutting-edge scientific research technology; an appreciation for human conservation, mediation, and preservation efforts; an appreciation for the global nature of scientific work; and the ability to collaborate and enter into relevant discourse with scientists across the globe.

Not only is the SEE-U program concerned with building knowledge, it is also designed to help students learn several key skills. According to CERC, these skills are a cornerstone of being a successful science student and later in a career as a professional working scientist. They include the ability to implement the scientific method and incorporate it into meaningful experiments; understanding primary statistical methodologies and the ability to conduct and select appropriate simple statistical analyses; knowledge of different field and laboratory techniques; the ability to gather data from a wide variety of sources and determine the relevance of that data; aptitude in preparing and presenting logical oral and written scientific research reports; the understanding of the importance of and the use of technological instrumentation to enhance scientific research; and the ability to communicate and collaborate with scientists across geographic divides.

\section{Contributions}

This paper represents an independent examination of an early and sizable transgeographic education project. It outlines a model that has been successful and is worthy of inspection. Although the SEE-U project focuses on global education in the area of science, the program has much broader implications across disciplines. This paper is meant to add to the current discussion of technology facilitated global education, and encourage further research and development.

\section{How the Study Was Conducted}

The author of this paper is not affiliated with the SEE-U program. This work represents an independent investigation conducted by an instructional technologist interested in the development and deployment of a technology facilitated transgeographic learning experience. The primary investigation began during the development and pilot testing of the program. The investigation was completed with follow up interviews conducted after the program had been running for a couple of years. The investigation involved the conduction of interviews with key individuals involved with the creation of SEE-U which included individuals affiliated with the Center for Environmental Research and Conservation, the Center for International Earth Sciences Information Network, the Columbia Center for New Media in Teaching and Learning, the Black Rock Forest, and the Black Rock Forest Consortium. Additional information was gathered through the review of internal and external documents.

\section{Limitations of This Study}

The most significant limitation of this study is that the author did not administer, nor have access, to student satisfaction surveys. Quantitative data of students' perceived satisfaction with the overall program, curriculum, technological components, and collaborative aspects would have brought to light strengths and weaknesses that were not evident during this examination. 


\section{Summary and Future Research}

Digital technologies are closing spatial and temporal gaps while engendering expansive new international communities. Replete with symbolic interactions, these transgeographic communities inspire new realms of educational possibility, allowing educators and learners to broaden perspectives through intellectual discourse and collaboration while helping to eradicate cultural divides.

The Summer Ecosystems Experience for Undergraduates (SEE-U) is a model of how technology can be used to this end. The SEE-U program operates at three geographically distinct locations concurrently and includes field research, global networking, GPS and GIS usage, real-time interactions, data collection, a globally networked geo-referenced digital database, data manipulation, online lectures, bulletin board discussions, Web-based office hours, links to relevant resources, expert presenters, online demonstration videos, networked simulations, collaborative research, and a series of student presentations.

The activities included in the SEE-U program have been designed to bridge the gaps between scientific practice and learning and to prepare the next generation of scientists to use cutting edge technologies, be active in global discourse, and collaborate with fellow scientists. As a result of its design, the SEE-U program provides an experience unrivaled in field-science education.

International programs are growing in popularity across the globe. This investigation has helped to inspire the beginning stages of the development of a technology facilitated global education project between the University of Maryland Eastern Shore and several countries located in SubSaharan Africa.

\section{References}

Bhatti, A., Tubaisahat, A., \& El-Qawasmeh, E. (2005). Using technology-mediated learning environment to overcome social and cultural limitations in higher education. Issues in Informing Science and Information Technology, 2. Available at http://2005papers.iisit.org/I06f77Bhat.pdf

Black, J. \& Kaplan, K. (2001). Computer-based tools for the development and investigation of scientific reasoning skills. In C. Montgomerie \& J. Vitelli (Eds.), Proceedings of EdMedia World Conference On Educational Multimedia, Hypermedia \& Telecommunications. Norfolk, VA: Association for the Advancement of Computing in Education.

Black, J., Hachey, A., \& Tsuei, L. (2001). Fostering mental-model thinking during design. In C. Montgomerie \& J. Vitelli (Eds.), Proceedings of EdMedia World Conference On Educational Multimedia, Hypermedia \& Telecommunications. Norfolk, VA: Association for the Advancement of Computing in Education.

Buzzetto-More, N. (2004). The Black Rock Forest consortium: A narrative. Ed.D. dissertation, Columbia University, New York.

Buzzetto-More, N. (2005, June 16-19). The IT Revolution: Applications and strategies for transgeographic learning and academia in the twenty-first century. Proceedings of the Informing Science and Information Technology in Education Conference 2005. Flagstaff, AZ. Available at http://proceedings.informingscience.org/InSITE2005/P02f104Buzz.pdf

Dede, C., Ash, K., M. Loftin, B., \& Salzman. (2000). In M. Jackobson \& R. Kozma, Innovations in science and mathematics education: Advanced designs for technologies of learning. Mahwah, NJ: Lawrence Erlbaum Associates.

Fenrich, P. (2005). What you can do to virtually teach hands on skills. Issues in Informing Science and Information Technology, 2. Available at http://2005papers.iisit.org/I28f14Fenr.pdf

Frederiksen, J. \& White, B. (2000). In M. Jackobson \& R. Kozma, Innovations in science and mathematics education: Advanced designs for technologies of learning. Mahwah, NJ: Lawrence Erlbaum Associates. 
Heterick, R.C., Jr., Mingle, J. R., \& Twigg, C. A. (1997). The public policy implications of a global learning infrastructure. Paper retrieved August 2003, from http://www.educause.edu/nlii/keydocs/policy.html

Johnson, S. D., \& Thomas, R. G. (1994, Winter-Spring). Implications of cognitive science for instructional design in technology education. Journal of Technology Studies, 20, 33-45. (EJ 494 218)

Kastens, K. (1999, March 3). Adding real-time data to the Black Rock Forest digital library to enable students to engage in predictiveiInvestigations. Unpublished Proposal to the National Science Foundation. New York, NY: Columbia University, Lamont Doherty Earth Observatory.

Koohang, A., \& Harmon, K. (2005). Open source: A metaphor for e-learning. Informing Science Journal, 8, 75-86. Retrieved from http://inform.nu/Articles/Vol8/v8p075-086Kooh.pdf

Lewis, B., MacEntee, V., DeLaCruz, S., Englander, C., Jeffrey, T., Takach, E., Wilson, S., \& Woodall, J. (2005). Learning management systems comparison. Proceedings of the 2005 Informing Science and IT Education Joint Conference. Available at http://proceedings.informingscience.org/InSITE2005/P03f55Lewis.pdf

McIssac, M. (1993, January). The global classroom: An international perspective. In: Proceedings of Selected Research and Development Presentations at the Convention of the Association for Educational Communications and Technology Education. Educational Resources Information Center. ERIC Identifier: ED3262186

McClintock, R. (1999). Educators manifesto: Renewing the progressive bond with posterity through the social construction of digital learning communities. Published Paper. New York, NY: Teachers College, Columbia University, Institute for Learning Technologies.

Sarapuu, T., Adojaan, K., Hirmo, C., Laane, T., Mallo, L., Pata, K., Pedaste, M., \& Puusepp, A. (n.d.). Designing visualized learning process through educational technology. Retrieved August 2003, from http://www.ut.ee/biodida/e/teadust.htm

Scalpeter, J. (1998). Interview with Cheryl Lemke. Ed Tech Research Forum. Technology and Learning Magazine.

\section{Biography}

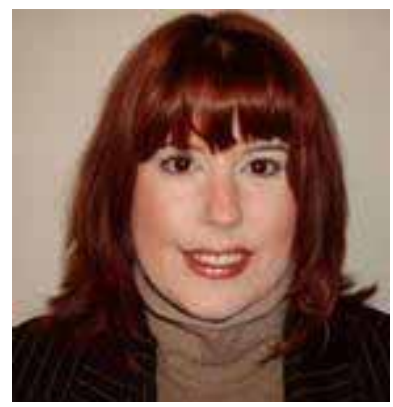

Dr. Nicole A Buzzetto-More has a doctorate in communications and instructional technology from Columbia University, a masters in education in communications and instructional technology from Columbia University, a masters of science in communications from the College of New Rochelle, and a bachelor of arts degree from Marist College. Originally from New York, she currently resides on the eastern shore of Maryland where she is a faculty member in the School of Business and Technology at the University of Maryland Eastern Shore. Her intellectual interests include the uses of digital technologies to augment teaching and learning. She has published a number of papers in referred journals and is a frequent presenter at conferences across the globe. In 2005, she was honored by the American Distance Education Consortium. She is currently working on her first book. 